\title{
Do Fluoroquinolones Cause Neuropathy?
}

\author{
Amer A Ghavanini* \\ Department of Medicine, University of Toronto, Canada
}

Submission: February 21, 2017; Published: March 23, 2017

*Corresponding author: Amer A Ghavanini, Head, Division of Neurology, Trillium Health Partners and Clinical Assistant Professor, Department of Medicine, University of Toronto, Canada, Email: amerghavanini@gmail.com

\section{Editorial}

Fluoroquinolone antibiotics are thought to be associated with peripheral neuropathy. Since 2004, the United States Food and Drug Administration (FDA) requires the manufacturers of systemic fluoroquinolone drugs to list peripheral neuropathy on the label for these drugs [1]. It further recommends that patients with symptoms of peripheral neuropathy after taking systemic fluoroquinolone to stop the medication and to be treated with an alternative non-fluoroquinolone antibacterial drug. This decision is based on FDA's review of the Adverse Event Reporting System (AERS) database. This data has been reviewed and published. The data shows that out of 46,257 adverse event reports submitted for fluoroquinolones, 539 reports involved peripheral neuropathy. Of these reported cases, 119 had at least one concomitant risk factor for peripheral neuropathy and 48 had Guillain-Barre syndrome.

Disproportionality analysis showed that the observed number of peripheral neuropathy and GBS were 2.70 and 3.22 times higher than the expected count of events for fluoroquinolones. AERS is a spontaneous reporting system. Therefore, while an association between fluoroquinolones and peripheral neuropathy is possible based on this data, a true association and the incidence of peripheral neuropathy in patients taking these antibiotics cannot be substantiated Coincidentally, the number of reported peripheral neuropathy in association with fluoroquinolones triple to quadrupled in the 7 years after FDA's announcement of label change (Figure 3), [1] and parallel to the launch of related lawsuits.

The earliest report of neuropathy in patients treated with fluoroquinolones is a review of 40 patients treated with ciprofloxacin from Sweden [2]. One of these patients reported subjective paresthesias. No objective evidence of neuropathy was provided in this report. Francis et al. [3] report a patient with diffuse pain and paresthesia that started shortly after a course of ciprofloxacin for UTI. Despite quite significant symptoms, no objective evidence of neuropathy was found including on nerve conduction studies and skin punch biopsy for small fibre neuropathy. From a neurological perspective, it is quite difficult to explain the reported case and the symptoms may have not been neurological in nature. While some cases of peripheral neuropathy subsequent to fluoroquinolone use are unsubstantiated, there are reports of neuropathy associated with fluoroquinolones with at least some objective findings. These reports can be divided into single case reports and larger studies.

Single cases of objectively substantiated neuropathy in the context of treatment with fluoroquinolones do exist. Auon et al [4] report a patient with objective evidence of axonal neuropathy, who was treated with multiple members of fluoroquinolones. However, the patient had past history of treatment with vincristine for Hodgkin's lymphoma and required months of treatment with fluoroquinolones for refractory osteomyelitis. Rollof \& Vinge [5] reported a patient with electro physiologically confirmed neuropathy several months after treatment with ciprofloxacin for osteomyelitis. This patient also had history of breast cancer, kidney dysfunction, systemic lupus erythematosis, and was treated with other medications such as chloroquine and NSAIDs. Schmidt et al. [6] report a patient with electro physiologically confirmed Guillain-Barre syndrome three days after starting ofloxacin, and relate the condition to treatment with this medication.

Cerebrospinal fluid analysis showed elevated protein, and an inflammatory polyradiculoneuropathy is more likely than a toxic peripheral neuropathy secondary to ciprofloxacin. Murray \& Wortmann [7] report another patient with Guillain-Barre syndrome confirmed with electrophysiological studies with onset 36 hours after initiating Trovafloxacin for the treatment of pneumonia complicated with empyema. This patient also had diabetes. A patient treated with a ciprofloxaxin was reported to experience burning feet sensation 24 hours after treatment [8]. Nerve conduction studies were normal, but thermal sensation thresholds were noted to be decreased in upper and lower limbs 
and therefore a diagnosis of small fibre neuropathy was made. Thermal sensation threshold is a somewhat subjective test, and further objective tests such as punch biopsy were not done to substantiate a small fibre neuropathy.

Larger studies such as reviews of adverse drug reaction from post-marketing databases or during clinical trials are available. An early review of 582 reports related to fluoroquinolones submitted to the Swedish Adverse Drug Reactions Advisory Committee identified 37 patients with peripheral neuropathy [9]. Only one of these patients had electro physiologically substantiated evidence of neuropathy. Eleven of these patients had concomitant factors known to be associated with peripheral neuropathy, 12 received concomitant treatment not known to be associated with neuropathy and four had previously experienced paresthesias in the context of using another medication. In six cases, the symptoms were unilateral. An internet survey was able to identify 45 patients reporting symptoms of possible peripheral neuropathy, and attributing it to fluoroquinolones [10].

This survey was difficult to interpret as the cases were simply based on unsubstantiated self-reports, and the number of the identified cases were small considering that about 11,000,000 fluoroquinolones were prescribed until the date of the study [11]. In a small clinical trial comparing ciprofloxacin with metronidazole, none of the patients receiving ciprofloxacin as compared to $33 \%$ of patients receiving metronidazole developed paresthesias [12]. In another small clinical trial comparing 16 patients with ulcerative colitis treated with a four-week course of ciprofloxacin and tinidazole versus a historic cohort, one of the patients developed transient paresthesias [13]. A peripheral neuropathy was not substantiated using electrophysiological studies. Finally, a study of patients with idiopathic peripheral neuropathy indicated an about two-fold increased relative risk of oral fluoroquinolones use within the year preceding the diagnosis [14-16]. While the most robust of all the above studies, this study used finasteride rather than another antibiotic as control. Therefore, it is not possible to know if the increased risk reflects a presence of infection requiring treatment with antibiotics within the preceding year or a true association between neuropathy and oral fluoroquinolones.

The accumulated data over years suggest a possible but not definite association between fluoroquinolones use and peripheral neuropathy. Prospective studies are required to further establish such association. In the absence of more robust data, the current recommendation by FDA is to monitor for the symptoms of neuropathy in patients receiving systemic fluoroquinolones and to discontinue the medication should such symptoms arise. These medications should be avoided in patients with past history of neuropathy symptoms in association with fluoroquinolones.

\section{References}

1. Ali AK (2014) Peripheral neuropathy and Guillain-Barré syndrome risks associated with exposure to systemic fluoroquinolones: a pharmacovigilance analysis. Ann Epidemiol 24(4): 279-285.

2. Karlman K (1988) (On behalf of Swedish Study Group) Therapy of acute and chronic gram-negative osteomyelitis with ciprofloxacin. Report from a Swedish Study Group. J Antimicrob Chemother 22(2): 221-228.

3. Francis JK, Higgins E (2014) Permanent Peripheral Neuropathy: A Case Report on a Rare but Serious Debilitating Side-Effect of Fluoroquinolone Administration. J Investig Med High Impact Case Rep 2(3): $1-4$.

4. Aoun M, Jacquy C, Debusscher L, Bron D, Lehert M, et al. (1992) Peripheral neuropathy associated with fluoroquinolones. Lancet 340(8811): 127.

5. Rollof J, Vinge E (1993) Neurologic adverse effects during concomitant treatment with ciprofloxacin, NSAIDS, and chloroquine: possible drug interaction. Ann Pharmacother 27(9): 1058-1059.

6. Schmidt S, Cordt-Schlegel A, Heitmann R (1993) Guillain-Barré syndrome during treatment with ofloxacin. J Neurol 240(8): 506-507.

7. Murray CK, Wortmann GW (2000) Trovafloxacin-induced weakness due to a demyelinating polyneuropathy. South Med J 93(5): 514-515.

8. Jumma OK, Dick J, Marshall A, Mellor K (2013) Ciprofloxacin induced acute small fibre neuropathy. Case report. Can J Neurol Sci 40(1): 127128.

9. Hedenmalm K, Spigset 0 (1996) Peripheral sensory disturbances related to treatment with fluoroquinolones. J Antimicrob Chemother 37(4): 831-837.

10. Cohen JS (2001) Peripheral neuropathy associated with fluoroquinolones. Ann Pharmacother.; 35(12): 1540-1547.

11. Tillotson GS (2001) Comment: peripheral neuropathy syndrome and fluoroquinolones. Ann Pharmacother 35(12): 1673-1674.

12. Shen B, Achkar JP, Lashner BA, Ormsby AH, Remzi FH, et al. (2001) A randomized clinical trial of ciprofloxacin and metronidazole to treat acute pouchitis. Inflamm Bowel Dis 7(4): 301-305.

13. Shen B, Fazio VW, Remzi FH, Bennett AE, Lopez R, et al. (2007) Combined ciprofloxacin and tinidazole therapy in the treatment of chronic refractory pouchitis. Dis Colon Rectum 50(4): 498-508.

14. Etminan M, Brophy JM, Samii A (2014) Oral fluoroquinolone use and risk of peripheral neuropathy: a pharmacoepidemiologic study. Neurology 83(14): 1261-1263.

15. Chan PC, Cheng IK, Chan MK, Wong WT (1990) Clinical experience with pefloxacin in patients with urinary tract infections. Br J Clin Pract 44(12): 564-567.

16. FDA (2013) FDA Drug Safety Communication: FDA requires label changes to warn of risk for possibly permanent nerve damage from antibacterial fluoroquinolone drugs taken by mouth or by injection. United States Food and Drug Administration, USA. 
CC C. This work is licensed under Creative
Commons Attribution 4.0 Licens

Your next submission with Juniper Publishers
will reach you the below assets
- Quality Editorial service
- Swift Peer Review
- Reprints availability
- E-prints Service
- Manuscript Podcast for convenient understanding
- Global attainment for your research
- Manuscript accessibility in different formats
( Pdf, E-pub, Full Text, Audio)
- Unceasing customer service
Track the below URL for one-step submission
https://juniperpublishers.com/online-submission.php

